\title{
CFD FLOW ANALYSIS OF THE CANTILEVER MICRO-TURBINE
}

\author{
TOMÁš SYKA ${ }^{a, *}$, Andreas P. Weiß ${ }^{b}$ \\ ${ }^{a}$ New Technologies - Research Centre (UWB), Univerzitni 8, Pilsen, Czech Republic \\ ${ }^{b}$ OTH Amberg-Weiden, Kaiser-Wilhelm-Ring 23, Amberg, Germany \\ * corresponding author: tsyka@ntc.zcu.cz
}

\begin{abstract}
The article deals with a description of results from research and development of the cantilever micro-turbine designed for the ORC power plants. The experimental turbine stage and used numerical models are briefly described. In the first part the comparison of measured and CFD results is presented. The second part deals with an investigation of the outlet geometry influence on the turbine working parameters. The results are relevant for next studies in the research and development process.
\end{abstract}

KEYwORDS: CFD simulation, NUMECA, ORC, cantilever micro-turbine.

\section{INTRODUCTION}

Organic Rankine Cycle (ORC) power plants are a viable option for decentralized small scale stationary energy converters $(<100 \mathrm{kWel})$ heated by e.g. waste heat in industry, waste heat of internal combustion engines, geothermal heat or even solar radiation. An ORC power plant works like a coal fired steam power plant: A steam power plant pumps water on high pressure, heats and evaporates it in the steam generator, expands the steam in a turbine which drives the generator and finally condenses it back to liquid state in a condenser. The difference of ORC to conventional steam cycle is that instead of water, another fluid like e.g. an alcohol, a refrigerant or siloxanes is used. More information about micro-turbines problematic in general can be found in [1] and [2].

This article deals with possibilities of CFD simulations of small turbines which usually work with fluids mentioned above. Gained results are compared to measured values from measurement on the test rig. Concretely, results from CFD simulations and measurement of the cantilever turbine with radial inlet direction into stator channels and axi-radial outlet from rotor are shown. As a working fluid hexamethyldisiloxane was used.

In order to investigate real characteristics the cantilever turbine was tested in the ORC research plant at the Center of Energy Technology at the University of Bayreuth.

Main goal of this article is to show evaluated turbine working parameters and find out the differences between computed and measured results. It is possible to evaluate many turbine stage parameters but for a purpose of this article we were focused on a total-tostatic efficiency evaluation computed from the torque and a turbine stage pressure ratio evaluation which are the most important parameters.

Next goal of our work was to find out an influence of the outlet casing geometry on the turbine efficiency and try to design more suitable shape of the outlet

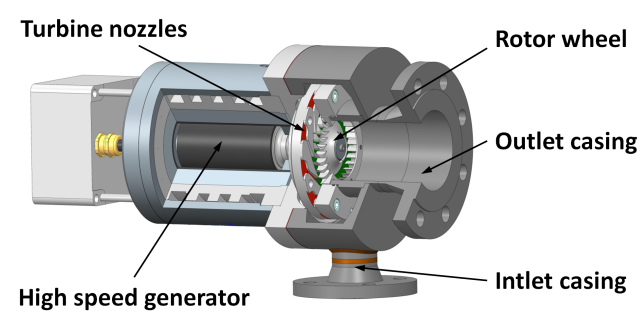

FigURE 1. Architecture of the radial inflow cantilever turbine.

casing because we were expecting large flow separation areas in this part.

\section{The TESTED TURBINE AND THE ORC RESEARCH PLANT}

Design of the cantilever micro-turbine is compact and simple in comparison to a general water steam turbine. It is necessary to develop a very flexible "construction kit" due to a wide range of temperature and pressure operating conditions dependent on a specific heat source. Architecture of the investigated turbine is shown in the Figure 1 .

The turbine design including generator is really compact and dimensions of the whole unit are relatively small. Maximum diameter of the rotor wheel is $120 \mathrm{~mm}$. Main parts of this unit are inlet casing, stator wheel with nozzles, rotor wheel, outlet casing and generator. At this point there are no sealings in the turbine to lower leakage losses.

In order to investigate real characteristics the cantilever turbine was tested in the ORC research plant at the Center of Energy Technology at the University of Bayreuth. The research plant was designed to investigate waste heat recovery from a $250 \mathrm{~kW}$ biogas internal combustion engine with an exhaust gas temperature of about $500{ }^{\circ} \mathrm{C}$.

Process simulations and theoretical investigations showed that for this rather high exhaust temperature hexamethyldisiloxane is a suitable working fluid [3] 


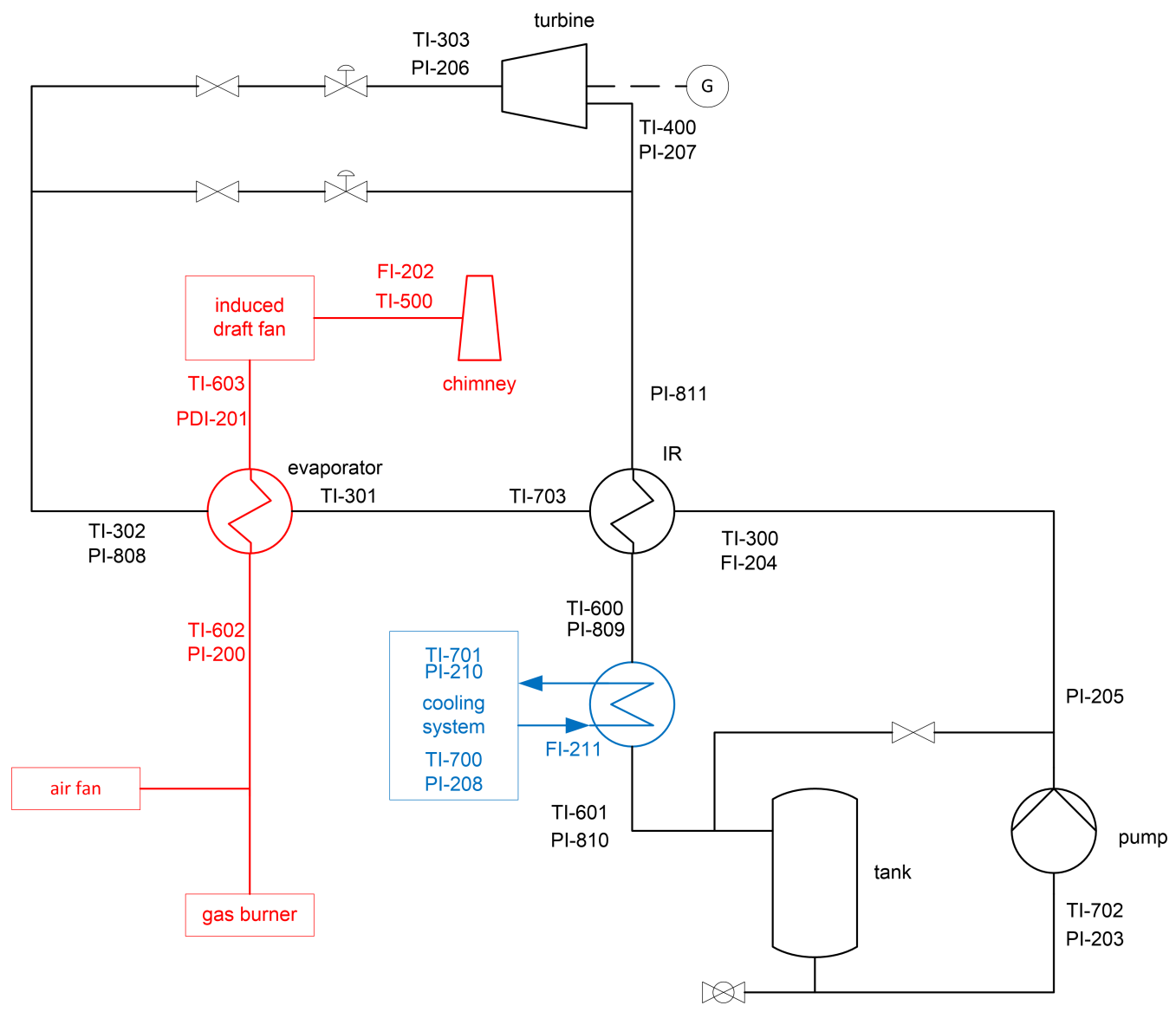

Figure 2. ORC plant layout.

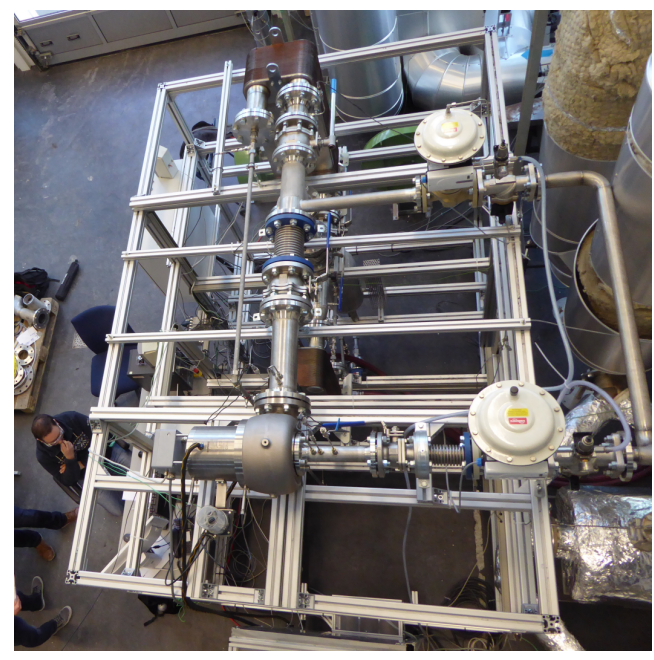

Figure 3. Photo of the ORC plant.

and 44. The layout of the research plant is shown in Figure 2. ORC plant consists of a feed pump, an evaporator, an expander, a recuperator and a condenser. However, the evaporator is directly heated by the exhaust gas and does not use an additional thermal oil loop.

The mass flow rate is measured by a Coriolis device ("FI-204" in Figure 2). Pressures (PI) and temperatures (TI) are measured upstream and downstream of each component. Thus, the efficiencies of all com- ponents can be calculated. For full load, i.e. high mass flow rates, the turbine efficiency can be calculated reliably on the basis of the measured turbine exit temperature. However, for small part load the heat losses are not negligible.

Therefore, to avoid using a measured exit temperature, the applied electrical conversion chain was investigated separately in advance. For this purpose, the generator was driven by an electric motor. A torque meter between motor and generator was used to measure torque and rotational speed to get knowledge about the mechanical power input. Electric power fed into the grid was measured by the $25 \mathrm{~kW}$ feed-in unit. Thus, the overall electrical efficiency of the entire electrical conversion chain could be determined as a function of power [5].

Discussed total-to-static isentropic turbine efficiencies (Eq. 1) use actual enthalpy drop determined by measured turbine power $\left(P_{\text {Tur }} / \dot{\mathrm{m}}\right)$ divided by the ideal total-to-static isentropic enthalpy $\operatorname{drop}\left(h_{t 0}-h_{s 2, i s}\right)$.

$$
\eta_{i s, t s}=\frac{P_{\text {Tur }}}{\dot{m}\left(h_{t 0}-h_{s 2, i s}\right)}=\frac{P_{e l}}{\dot{m} \eta_{e l}\left(h_{t 0}-h_{s 2, i s}\right)}
$$




\section{CFD SETUP AND MESH PARAMETERS}

\subsection{Micro-turbines CFD Simulation ISSUES}

CFD simulations of micro-turbines have specifics given by turbines functional principle. Working medium is entering into the turbine with a low velocity and high pressure values but the expansion to very low pressure occurs already in the stator nozzles. This is connected with a high flow velocity increase. Flow velocity at the stator nozzles outlet is supersonic and Mach number value is usually higher than 2.5. Gained kinetic energy is afterwards transformed in the rotor wheel into work.

Flow velocity increase is achieved by a special stator nozzles geometry. In case of water steam turbine we could talk about stator blades but in case of microturbines the stator nozzles are relatively long and their shape is similar to the Laval nozzle. The stator nozzles geometry of the investigated turbine is also characteristic by its non axi-symmetric cross-section. Due to this reason non-standard demands are placed on a grid generator abilities.

Rotor blades geometry is not much interesting on the first sight but due to high rotor inlet velocity it is necessary to design a correct blade geometry at the leading edge.

High Mach numbers and the presence of shock waves bring complications in modeling of the flow transition between static and rotating domains of the microturbine. In rotating machinery simulation the interface type "stage" is usually used because it is not necessary to keep the same pitch on both sides of the interface. But unfortunately in our case this interface type fails because "stage" can't handle shock waves deflections from interface boundary condition at such high flow velocities. So we had to use the interface type "frozen-rotor" whose disadvantage is a necessity to model the same domain pitches on both sides of the interface and a consequence of this is the computational grid with higher number of cells.

Complications connected to presence of shock waves wasn't removed totally since they were reduced to a local error but the stable solution was achieved. We have tested this behavior in ANSYS FLUENT 18, ANSYS CFX 18 and NUMECA FINE/Turbo 11. The results were more or less the same with similar error.

Due to high changes of physical properties of working gas (hexamethyldisiloxane) in the micro-turbine domain it is suitable to use some variant of medium real gas model instead of usually used ideal gas model.

Main problematic points of the micro-turbine CFD simulations are:

- Higher demands on the mesh quality and grid generator abilities.

- Properties of working medium are defined by real gas model or by thermodynamic tables.

- Simulation of flow field with high Mach numbers.

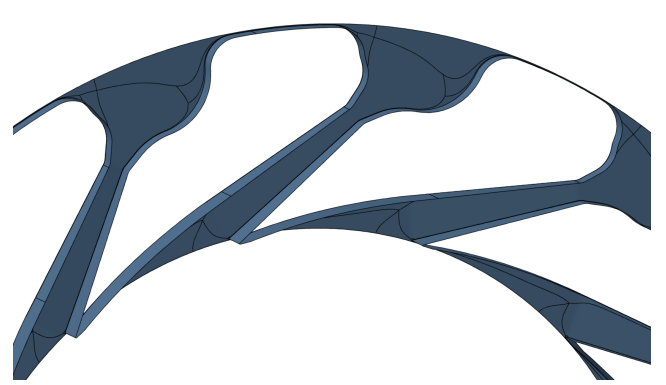

Figure 4. Stator nozzles.

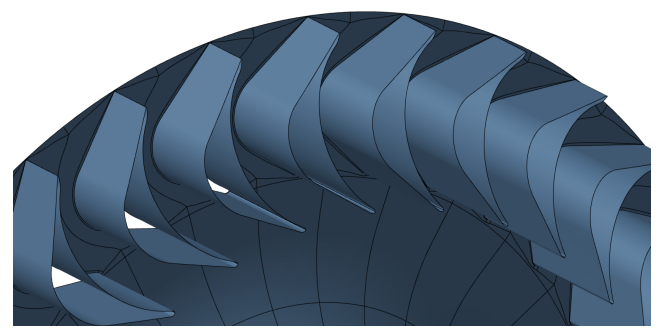

Figure 5. Rotor blades.

- It is not possible to avoid local physical errors at the rotor-stator interface due to the shock waves deflection.

- Presence of shock waves increases the computational time of the CFD simulation.

Taking into account these points we chose the NUMECA FINE/Turbo software package to prepare, compute and evaluate solved cases. NUMECA AutoGrid5 $5^{T M}$ is a full automatic hexahedral grid generator for all types of rotating machinery: complex axial, radial, and mixed-flow configurations. It is also able to mesh leakage domains and non axi-symmetric domains automatically. Properties of the working fluid are defined by generated tables in NUMECA TabGen.

\subsection{MESh PARAMETERS}

As was mentioned we used the NUMECA AutoGrid5 $5^{T M}$ to create the computational mesh. The main asset of the AutoGrid5 mesh generator is a possibility to create channel and leakage meshes almost automatically. General geometries such as the turbine inlet casing had to be meshed manually. The resulting mesh is hexahedral and multi-block structured. These properties allow to solver to take advantage of the multigrid computation approach. Multigrid simulations with a structured mesh usually converge faster than a solution with a unstructured mesh.

To achieve precise results we had to create a mesh with good cells quality. The height of the first cells at the wall was $0.0005 \mathrm{~mm}$ and this corresponds to maximum $y^{+}$value of 3.24 . We used 77 cell layers in 


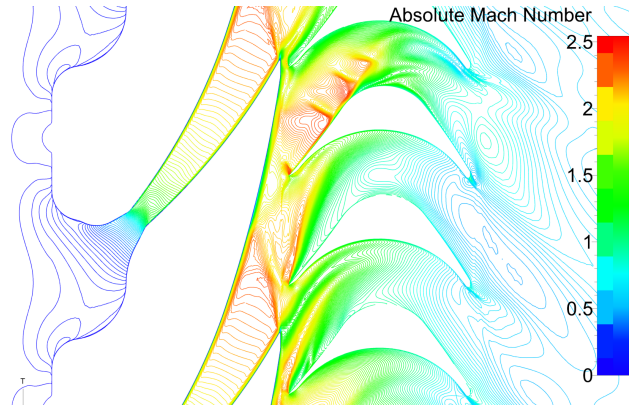

Figure 6. Isolines of Mach number.

the radial direction in the main channel domains. The maximum cell expansion ratio was 3.5 and orthogonal quality was over 20 (higher is better up to maximum of 90$)$.

\subsection{InVESTIGATION OF THE INLET CASING INFLUENCE ON THE TURBINE PERFORMANCE}

At the beginning of the turbine model preparation we had to check a possible level of the geometry simplification due to a computational time saving. Main question was if it is necessary to keep the turbine inlet casing in the model because the inlet casing domain is not rotationally periodic. To be able to make decision we had to create simplified and also complete micro-turbine model and compare simulation results.

Simplified model covers two stator nozzles, five rotor wheel channels, leakage domains and the outlet casing and it's mesh consists of 32 mil. of cells. This model is shown in the Figure 9

The complete model of the micro-turbine is shown in the Figure 7. In this case the mesh consists of 220 mil. of cells.

Comparison of the results from the simulations of both variants showed us that the turbine efficiency evaluated from the complete model is lower approximately by $0.15 \%$ than the efficiency of the simplified model. This difference is caused by friction losses in the inlet casing and more realistic flow field behavior in the outlet casing. In case of the complete model the outlet flow field is not affected by the periodic boundary condition.

The flow velocity magnitude at the stator nozzles inlet was quite low $\left(6 \mathrm{~ms}^{-1}\right)$ so we wasn't expected variable influence on the turbine stage parameters if there would be some diversion of the inlet flow distribution. To confirm that we did analysis of the velocity magnitude profiles at the stator nozzles outlet. The evaluation showed that the flow distribution is not almost affected by inlet casing and the fact that the distribution is mainly affected by actual rotor blades position. From this reason we decided to neglect inlet casing in the model and to use only simplified version for the further simulations.

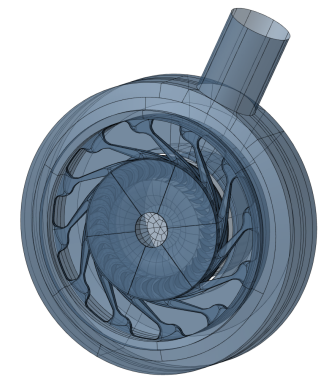

Figure 7. Complete model of the cantilever microturbine.

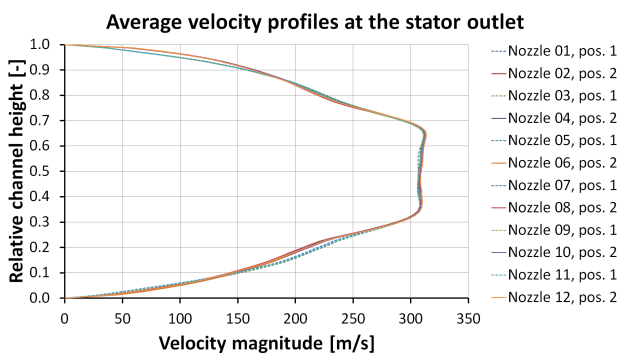

FiguRE 8. Velocity profiles at the stator outlet.

\subsection{BOUNDARY CONDITIONS}

In the Figure 9 the boundary conditions applied on the simplified micro-turbine model are shown.

At the stator inlet a total pressure and total temperature boundary conditions were used. At the exit from the outlet casing an average static pressure was used. Also an angular velocity was defined on rotating domains and surfaces. For the purpose of our study we used SST k- $\omega$ as a default turbulence model but we were expecting separated flow structures in the outlet casing so we also used more complex EARSM turbulence model which better describes a flow field separation or an adhesion on walls.

\section{Results And Discussion}

\subsection{Comparing CFD Results to MEASURED VALUES}

As it was mentioned in the introduction the main goal of our work was to do CFD analysis of the cantilever micro-turbine and compare achieved results with measured data. We also used two different turbulence models - SST k- $\omega$ and EARSM - in our simulations but we found that it won't be simple to compare simulated and measured data because of the way how a pressure in the outlet casing was measured. There was only one pressure gauge on the wall determined for the static pressure measuring. In CFD there are of course many ways how to evaluate certain variables - an area or a mass flow weighted average, simple average or just evaluating in the specified point. But problem is that user has no possibility to define the static pressure boundary condition as a point boundary condition. To achieve solution similar to measurement we had 


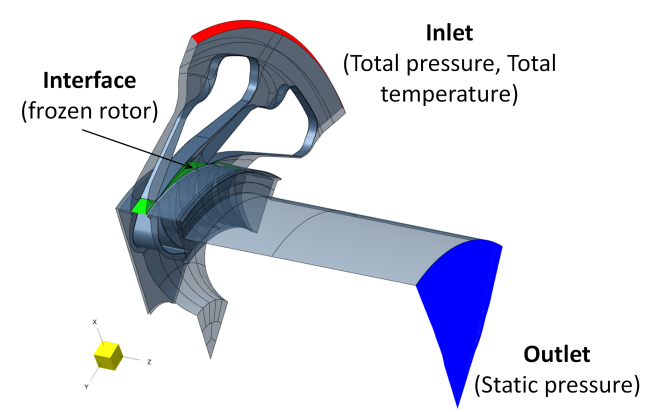

Figure 9. Boundary conditions.

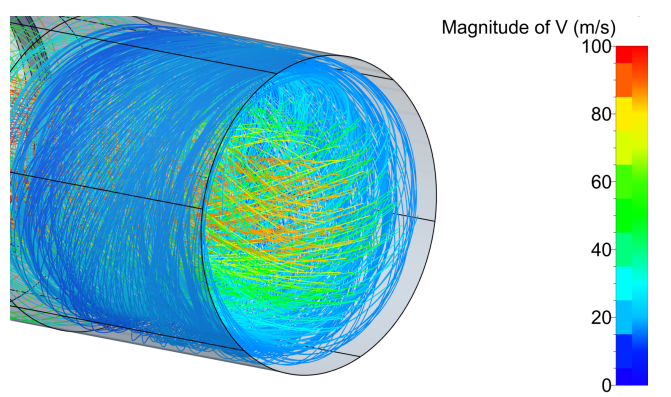

Figure 10. Outlet velocity streamlines.

to literally try to setup the outlet pressure in loops until the needed static pressure in specified point on the outlet casing wall was obtained.

The second thing is that there is high probability of the outlet static pressure measuring inaccuracy. The outlet casing is wide opened and the pressure gauge is probably located in an area with the massive flow separation. Also it would be better to measure the pressure in more locations than one. The pressure gauge location is indicated in the Figure 11.

In following figures the flow field in the cantilever turbine with $28000 \mathrm{rpm}$ is showed. It is a meridional averaged velocity in a meridional plane. The red lines show a flow direction and flow separations from the wall. Figure 12 shows simulation results with the SST k- $\omega$ turbulence model used and Figure 13 shows flow field from the simulation with EARSM. There is obvious difference of the flow field character in the outlet casing.

In case of simulation results with the SST k- $\omega$ turbulence model, the separated flow attaches back to the wall but in case of EARSM turbulence model the separated flow is separated in the whole outlet domain. Similar behavior can be seen also in other working characteristic operation points. Unfortunately we don't have measurement yet which could help us to decide which solution is correct. Meanwhile we are inclined to the solution with the EARSM turbulence model which more precisely models complex flow structures. The nature of the outlet flow field influences total efficiency of the cantilever turbine. Comparison of results from both simulated variants with measured data is shown in Figure 14

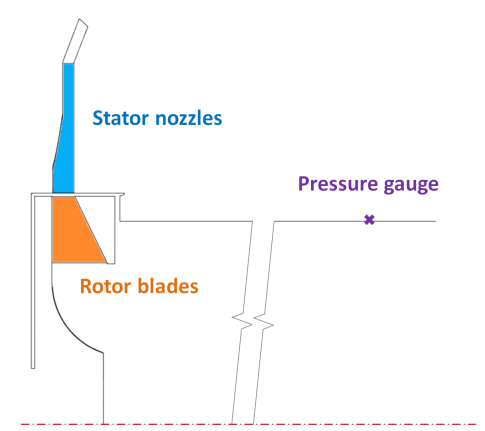

Figure 11. Approximate location of the pressure gauge.

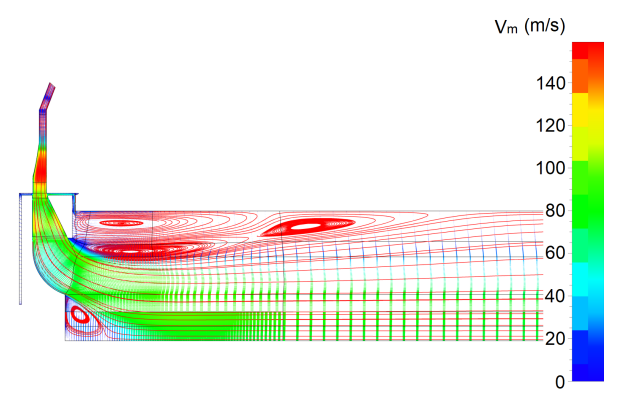

Figure 12. $28000 \mathrm{rpm}, \mathrm{SST} \mathrm{k}-\omega$.

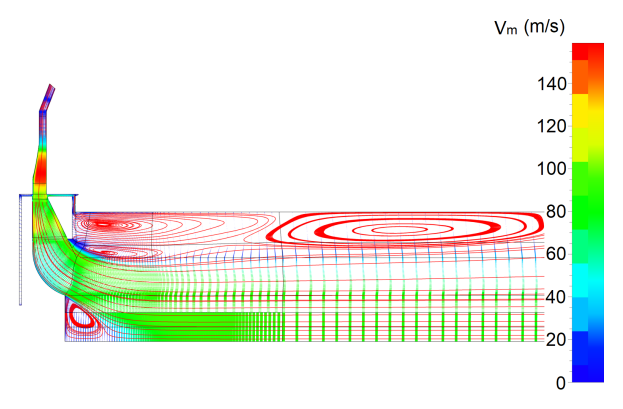

FigURE 13. 28000 rpm, EARSM.

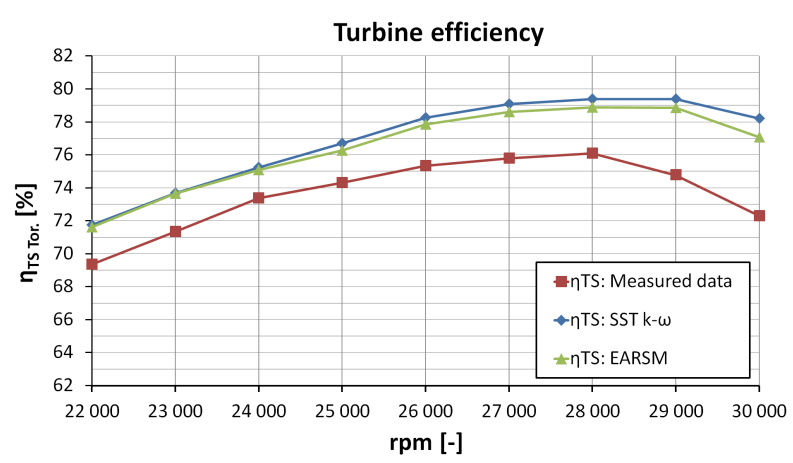

Figure 14. Comparison of achieved results. 


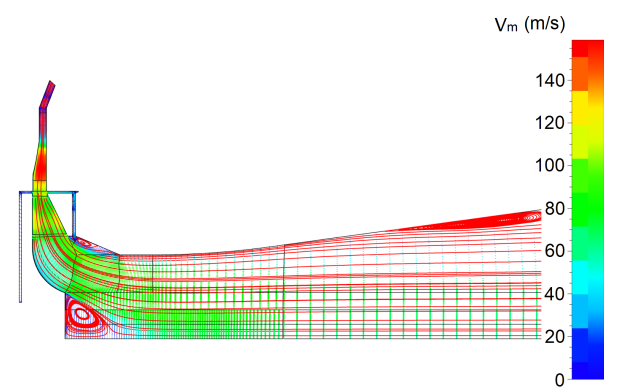

Figure 15. CFD results with the new outlet casing geometry.

Figure shows quite big differences between the results from CFD simulations and measured values. The efficiency difference is in the range from 2 to $4 \%$. As we expected efficiencies with the EARSM turbulence model are lower approximately by $0.4 \%$ than with the SST k- $\omega$. Big difference between computed and measured values can be caused by the inaccuracy of the outlet pressure measuring and by local inaccuracy on the rotor-stator interface. But the shape of characteristics is similar in all cases so it is possible to use CFD simulations for the investigating of the influence of several geometry changes on the turbine parameters.

\subsection{Influence OF THE OUTLET CASING GEOMETRY}

As it was indicated in previous chapter the current construction design of the outlet casing of the cantilever turbine is not optimal. There are large structures of the separated flow in outlet and this causes a decrease of the turbine efficiency. We tried to design better outlet casing geometry in which a smoother transition between rotor and outlet surfaces was applied. Current geometry was replaced by the diffuser as it is shown in the Figure 15. We successfully increased the cantilever turbine efficiency approximately by $1 \%$ with this new geometry.

\section{Conclusions}

We succeeded in the CFD simulating of the cantilever micro-turbine but we encountered some limits in a form of the local inaccuracy at the interface between stator and rotor turbine domains which probably affects an overall simulation results. This physical inaccuracy is caused by the shock wave deflection on the interface. For a purpose of this work we tested several CFD software but an achieved results were similar. Next factor affecting results of this work is probably the very simple pressure measuring at the micro-turbine outlet where some deviation in the measured values can occur. Based on the achieved results the new outlet casing geometry was designed. This helped to increase the cantilever micro-turbine efficiency by $1 \%$. Results are relevant for next studies in the research and development process.

\section{LIST OF SYMBOLS}

$V$ Velocity $\left[\mathrm{m} \mathrm{s}^{-1}\right]$

$p$ Pressure $[\mathrm{Pa}]$

$t$ Temperature $\left[{ }^{\circ} \mathrm{C}\right]$

$h$ Enthalpy $\left[\mathrm{J} \mathrm{kg}^{-1} \mathrm{~K}^{-1}\right]$

$\dot{m}$ Mass flow $\left[\mathrm{kg} \mathrm{s}^{-1}\right]$

$P$ Power [W]

$\eta \quad$ Efficiency [\%]

Ma Mach number

$y^{+}$Dimensionless wall distance

\section{ACKNOWLEDGEMENTS}

The work has been supported by the grant project Ziel - ETZ INTERREG V Project 53 Grenzüberschreitendes F\&I Netzwerk für Energieeffizienz und Kraft-Wärme(Kälte)-Kopplung / Přeshraniční sít pro výzkum a inovace v oblasti energetické účinnosti a kombinované výroby tepla a elektřiny $(2016-2020)$.

\section{REFERENCES}

[1] A. P. Weiß. Micro turbine generators for waste heat recovery and compressed air energy storage. $15^{\text {th }}$ conference on Power System Engineering,

Thermodynamics \& Fluid Flows - ES2016 2016. Pilsen, Czech Republic.

[2] A. P. Weiß. Volumetric expander versus turbine - which is the better choice for small rc plants? 3rd International Seminar on ORC Systems (22):301-310, 2015. http://www . asme-orc2015.be/content/publication

[3] M. Preißinger, D. Brüggemann. Thermal stability of hexamethyldisiloxane $(\mathrm{mm})$ for high-temperature organic rankine cycle (orc). Energies 9(183), 2016. DOI:10.3390/en9030183

[4] M. Preißinger, J. Schwöbel. Multi-criteria evaluation of several million working fluids for waste heat recovery by means of organic rankine cycle in passenger cars and heavy-duty trucks. Applied Energy 206:887-899, 2017. DOI:10.1016/j.apenergy.2017.08.212

[5] T. Turunen-Saaresti. Design and testing of high temperature micro-orc test stand using siloxane as working fluid. Journal of Physics: Conference Series (821), 2017. DOI:10.1088/1742-6596/821/1/012024. 